\section{Grafting Eggplant onto Tomato Rootstock to Suppress Verticillium dahliae Infection: The Effect of Root Exudates}

\author{
Na Liu and Baoli Zhou ${ }^{1}$ \\ College of Horticulture, Shenyang Agricultural University, Shenyang, \\ Liaoning 110161, China
}

Xin Zhao

Department of Horticultural Sciences, University of Florida, Gainesville, FL 32611

\section{Bo Lu}

The Information Research Institute, Shanghai Academy of Agricultural Sciences, Shanghai 201106, China

\section{Yixiu Li and Jing Hao \\ College of Horticulture, Shenyang Agricultural University, Shenyang 110161, China}

Additional index words. allelopathic suppression, disease resistance, GC-MS analysis, grafting, Solanum lycopersicum, Solanum melongena, verticillium wilt

\begin{abstract}
Verticillium wilt (caused by Verticillium dahliae), a soilborne disease, often causes significant reductions of yield in eggplant (Solanum melongena L.) production where crop rotation is limited. Rootstock replacement through grafting is considered an effective method to control this disease. This 2-year study investigated the eggplant yield, resistance to verticillium wilt, and allelochemicals in root exudates of eggplant grafted onto a tomato rootstock. Both disease incidence and disease severity on grafted eggplant were markedly lower than those of nongrafted eggplants. Fifteen days after $V$. dahliae inoculation, grafted eggplants did not exhibit any infection, whereas the disease incidence and disease severity index of the nongrafted eggplants were $68.3 \%$ and $37.8 \%$ in 2006 and $66.7 \%$ and $36.3 \%$ in 2007 , respectively. Twenty-five days after inoculation, disease incidences on grafted eggplants were only $8.1 \%$ and $9.5 \%$ in 2006 and 2007 , respectively, but those of the nongrafted eggplants increased to $100 \%$. As a result, early yield, total yield, and average fruit weight were significantly increased by grafting when inoculated with $V$. dahliae in 2006 and 2007. Mycelium growth of $V$. dahliae was inhibited by the root exudates of grafted eggplants. In contrast, the root exudates of nongrafted eggplants enhanced the mycelium growth. The gas chromatography-mass spectrometry analysis revealed that the composition in the root exudates released by grafted eggplants differed not only from the nongrafted eggplants, but also from the tomato rootstock plants. Ten chemical classes were isolated and identified in root exudates of grafted eggplants. Carbazoles, amines, azulene, and fluorene were only detected in the grafted eggplants. The relative contents of ester compounds were the highest in the root exudates from the grafted eggplant followed by derivatives of benzene, whereas the relative contents of benzene derivatives were much higher than that of the ester compounds in the root exudates from the nongrafted eggplant and tomato rootstock.
\end{abstract}

\footnotetext{
Received for publication 30 June 2009. Accepted for publication 13 Oct. 2009 .

This work was financially supported by the National Natural Science Foundation of China (30771469), the National 863 of China (2004AA247010), the 11th Five-Year Key Support Programs for Science and Technology Development of China (2008BADA6B02), and the Innovation Group of Higher Education of Liaoning Province (2009T087), China.

We thank Drs. William M. Stall and Edward E. Carey for reviewing the manuscript.

${ }^{1}$ To whom reprint requests should be addressed; e-mail zblaaa@163.com.
}

Eggplant (Solanum melongena L.) is a major vegetable crop worldwide. Considerable yield loss under continuous monocropping in commercial eggplant production is often caused by soilborne diseases, particularly verticillium wilt (caused by Verticillium dahliae). Approximately $30 \%$ to $40 \%$ of the reduction in Chinese eggplant production has been ascribed to verticillium wilt (Wang et al., 2005). Symptoms of verticillium wilt on eggplant include yellow-bronze-wilted areas, mainly between the leaf veins, and vascular discoloration, which may result in stunted plant growth (O'Brien, 1983) and significant yield loss (Bletsos et al., 1999). Verticillium dahliae infects eggplants through the roots and overwinters in the form of microsclerotia in the soil. Control of verticillium wilt by chemical fungicides has not been very successful, especially on infected plants. In addition, because of the environmental concerns posed by chemical pesticides, proactive cultural practices are often recommended, including crop rotation (Garber, 1973), solarization (Morgan et al., 1991), resistant cultivars (Kalloo, 1993), and grafting eggplant onto resistant rootstocks (Lockwood et al., 1970; Oda, 2007). Many reports have suggested that using appropriate rootstocks can control the eggplant verticillium wilt effectively (Bletsos et al., 2003; Wang et al., 2004; Zhao et al., 1997; Zhou et al., 1997). Although wild species, including Solanum torvum Sw. and Solanum sisymbriifolium Lam., have been demonstrated as potential eggplant rootstocks with high resistance to verticillium wilt (Alconero et al., 1988; Bletsos et al., 2003; Zhou et al., 1997), using resistant tomato (Solanum lycopersicum L.) rootstocks was also shown to be effective (Lockwood et al., 1970; Wang et al., 2003b; Zhou and Wang, 2002). Production of wild eggplant rootstock seedlings can be very challenging as a result of low germination rate of seed, poor emergence, and slow early growth, whereas such issues may be resolved by the use of selected tomato rootstocks.

Among other mechanisms for resistance of grafted eggplants to $V$. dahliae, the allelopathic suppression exhibited by the root exudates from the grafted eggplants has been suggested to play a unique role (Zhou et al., 2001). Root exudates from grafted eggplants were shown to directly inhibit the spore germination and mycelium growth. It is well known that allelochemicals can be released through root exudation. Allelochemicals released from plants are primarily secondary metabolites, which can exhibit positive or negative effects on recipient plants or microorganisms (Rice, 1984). The synthesis and exudation of allelochemicals, along with increased overall production of root exudates, is typically enhanced by stress conditions that the plant encounters (Pramanik et al., 2000). Root exudates also represent one of the largest direct inputs of plant chemicals into the rhizosphere environment (Bertin et al., 2003). Allelochemicals in root exudates can influence plant growth through their impact on the rhizosphere microbial community. It is hypothesized that the compositions and contents of allelochemicals in root exudates after grafting may lead to enhanced disease resistance of eggplants to verticillium wilt. However, to date, little is known with respect to the allelochemicals in root exudates of grafted eggplant.

Elucidating the effect of root exudates on disease resistance of grafted eggplants would open a possible avenue for understanding vegetable grafting mechanisms and could facilitate rootstock selection. The objectives of this study were to investigate the suppression of $V$. dahliae by root exudates of grafted eggplants and further identify the allelochemical 
constituents of grafted eggplants using tomato as the rootstock.

\section{Materials and Methods}

Plants, cultural conditions, and experimental design. Xi'anlu, a commercially available eggplant cultivar, was used as the scion, whereas Lydl, a local tomato cultivar with identified resistance to verticillium wilt, was used as the rootstock. The experiment was carried out in a nonheated plastic greenhouse during 2006 and 2007 in the Vegetable Crops Experimental Station at the Shenyang Agricultural University. Scion and rootstock seeds were sown into sterilized medium consisting of 3 perlite: 2 peatmoss: 1 vermiculite (by volume) on 8 Feb. and 10 Mar. 2006 and 13 Feb. and 17 Mar. 2007, respectively. When the rootstock seedlings reached fourto five-leaf stage (13 Apr. 2006 and 23 Apr. 2007), grafting was carried out using the cleft method (Wang et al., 2003a). After 17d healing (1 May 2006 and 10 May 2007), the grafted eggplant seedlings were transplanted into $20.5-\mathrm{cm}$ diameter containers with the same sterilized substrate mixture as used for seedling germination and cultured in the greenhouse. Nongrafted eggplant and tomato plants were also grown to use as controls. The plants were grown under natural lighting in the greenhouse. Pots were placed on the ground where the ground soil was a sandy loam. Each plant was supplied with $500 \mathrm{~mL}$ Hoagland nutrient solution twice a week. The treatments were arranged in a randomized complete block design with three replications. Each replication consisted of 10 plants per treatment in both years.

Disease evaluation and yield. Five $\mathrm{d}$ after transplanting, a spade was vertically inserted into the rhizosphere $\approx 3 \mathrm{~cm}$ from the base of the stem for injuring the roots in each pot, and then the $V$. dahliae spore suspension $\left(1 \times 10^{7} /\right.$ $\mathrm{mL}$ ) was artificially injected into the rhizosphere along the same path to infect the roots. The $V$. dahliae isolate from infected eggplants was cultured in a 1-L glass jar containing $300 \mathrm{~mL}$ potato dextrose medium for $7 \mathrm{~d}$ at $25^{\circ} \mathrm{C}$. The inoculum suspension was adjusted to $1 \times 10^{7}$ spores $/ \mathrm{mL}$ with sterile distilled water. Each plant from the grafted eggplant, nongrafted eggplant and tomato treatments were inoculated with $100 \mathrm{~mL}$ of the pathogen suspension. With the onset of verticillium wilt symptoms, disease incidence and disease severity were evaluated every $5 \mathrm{~d}$ using the following calculations:

Disease Incidence =

$$
\frac{\text { Number of Infected Plants }}{\text { Total Number of Plants }} \times 100 \%
$$

Disease Severity Index $=$

\section{$\sum$ (Progression $x$}

Number of Infected Plants)

Total Number of Plants $X$ $\times 100 \%$

Highest Progression

Disease symptoms were classified into five categories based on the proportion of the yellow-bronze-wilted leaves in a plant (Wang et al., 2006), i.e., $0=$ no wilted leaves; $1=$ less than $25 \%$ of plant leaves wilted; $2=$ $25 \%$ to $50 \%$ of plant leaves wilted; $3=50 \%$ to $75 \%$ of plant leaves wilted; $4=75 \%$ to $100 \%$ of plant leaves wilted.

Both early and total yields were measured and average fruit weight determined. Early yields were measured from harvests during 20 June to 12 July in 2006 and 3 July to 30 July in 2007.

Collection of root exudates. Root exudates were collected at bud stage on 25 May 2007 using the root soaking method (Wang et al., 2005). Three plants randomly selected from each treatment were removed from the pots and the roots were washed carefully in tap water followed by distilled water to remove substrate. The roots of each plant were placed in beakers wrapped with black plastic film and containing $500 \mathrm{~mL}$ distilled water, leaving the root in darkness and the shoot exposed to ambient light conditions. After $10 \mathrm{~h}$ culturing under continuous aeration, the roots were carefully removed from the beaker. Then another three plants from each treatment were transferred into the same beakers as aforementioned. The incubation was repeated three times. Because of the water loss through leaf transpiration, the ultimate volume of solutions was brought to $500 \mathrm{~mL}$ with distilled water. The solution in each beaker was then filtered and the resulting root exudates extracted with an equal volume of ether in a separatory funnel. The aqueous fraction in the separatory funnel was re-extracted twice in equal volumes of ether. Supernatants for each sample were combined and filtered through anhydrous sodium sulfate into conical flasks and concentrated to 5 $\mathrm{mL}$ under vacuum at $40^{\circ} \mathrm{C}$. The concentrated extract was used to test the suppression of $V$. dahliae and identify the allelochemicals in the root exudates (He et al., 2005).

Test of effects of root exudates on growth of $\mathrm{V}$. dahliae. One milliliter of the root exudate extract from each treatment, i.e., grafted eggplant, nongrafted eggplant, and tomato rootstock, was added to $49 \mathrm{~mL}$ potato dextrose agar (PDA) cultural medium (sterilized and cooled to $40{ }^{\circ} \mathrm{C}$ ) and the mixture was poured to a culture plate. PDA mixed with $1 \mathrm{~mL}$ distilled water was used as a control. There were four replicated plates in each treatment and the control. A 6-mm diameter, pure cultured $V$. dahliae spot on PDA was then inoculated into the plates and incubated at $24{ }^{\circ} \mathrm{C}$ in darkness. The mycelium growth of $V$. dahliae was evaluated using the growth rate method (Zhang et al., 2006). Briefly, the colony diameter was measured with the cross method after $10 \mathrm{~d}$. The results were expressed in RI (allelopathic index) value. Williamson and Richardson (1988) defined RI in their article as:

$$
\begin{aligned}
& \text { If } \mathrm{T} \geq \mathrm{C}, \text { then } \mathrm{RI}=1-\mathrm{C} / \mathrm{T} \\
& \text { If } \mathrm{T}<\mathrm{C} \text {, then } \mathrm{RI}=\mathrm{T} / \mathrm{C}-1
\end{aligned}
$$

where $\mathrm{C}$ is colony diameter of the control; $\mathrm{T}$ is colony diameter of the treatment; and
RI $>0$ indicates stimulation, whereas RI $<$ 0 indicates inhibition. The intensity of effect was expressed in RI value.

Gas chromatography-mass spectrometry analysis of root exudate extracts. Root exudate extracts were analyzed by gas chromatography-mass spectrometry (GC-MS) (6890GC/ 5973MSD; Agilent Co., Santa Clara, CA) using an HP-5MS capillary column (30 $\mathrm{m} \times$ $0.32 \mathrm{~mm}, 0.25 \mu \mathrm{m}$ film). One microliter of the extract was injected. The carrier gas was helium at a constant flow rate of $1 \mathrm{~mL} \cdot \mathrm{min}^{-1}$, and the GC oven temperature was programmed as follows: from $60{ }^{\circ} \mathrm{C}$ to $140{ }^{\circ} \mathrm{C}$ at the rate of $10^{\circ} \mathrm{C} / \mathrm{min}$, held for $2 \mathrm{~min}$, and increased to $220^{\circ} \mathrm{C}$ at a rate of $15^{\circ} \mathrm{C} / \mathrm{min}$, held for $2 \mathrm{~min}$, then up to $240{ }^{\circ} \mathrm{C}$ at a rate of $20^{\circ} \mathrm{C} /$ min and held for $10 \mathrm{~min}$. The injector temperature was maintained at $220{ }^{\circ} \mathrm{C}$. Ion source voltage was at $70 \mathrm{eV}$, and temperature was at $230{ }^{\circ} \mathrm{C}$. The mass range was scanned from 30 to $600 \mathrm{~m} / \mathrm{Z}$.

Statistical analysis. Analysis of variance was performed using the Data Processing System software (Refine Information Tech. Co., Ltd., Beijing, China). Significant differences among treatments were determined by Fisher's least significant difference test at $P \leq 0.05$. Component identification of the root exudates extract was carried out based on the NIST mass spectral library (U.S. National Institute of Standards and Technology, Gaithersburg, MD) 98 version. The relative content of each component was calculated according to the area normalization method, which is the ratio of the peak area of a particular compound to the total peak area of all compounds.

\section{Results}

Resistance to verticillium wilt and yield. Eggplant grafted onto tomato rootstock exhibited markedly higher disease resistance than nongrafted eggplant when challenged with $V$. dahliae (Table 1). On 20 May 2006 and 30 May 2007, 15 d after inoculation, grafted eggplant and tomato rootstock plants were not infected, whereas disease incidence and disease severity index on nongrafted eggplant plants were $68.3 \%$ and $37.8 \%$ in 2006 and $66.7 \%$ and $36.3 \%$ in 2007 , respectively. All nongrafted eggplant plants were infected $25 \mathrm{~d}$ after inoculation by 30 May 2006 and 9 June 2007 with a severity index of $79.8 \%$ and $81.5 \%$, respectively. In contrast, only $8.1 \%$ and $9.5 \%$ of the grafted eggplants were infected in 2006 and 2007, respectively, not significantly different from the tomato rootstock plants. Compared with the nongrafted eggplant, grafted eggplant with the tomato rootstock showed significant increases in early yield, total yield, and average fruit weight when inoculated with V. dahliae in both 2006 and 2007 (Table 2).

Suppression of V. dahliae by root exudates from grafted eggplants. Mycelium growth was inhibited in the presence of root exudates from grafted eggplant and tomato rootstock plants (Table 3 ). As indicated by both colony diameter and RI values, the allelopathic inhibitory effects of 


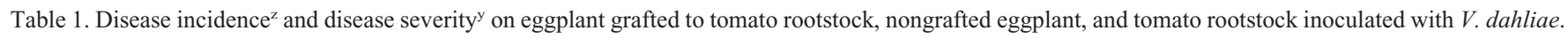

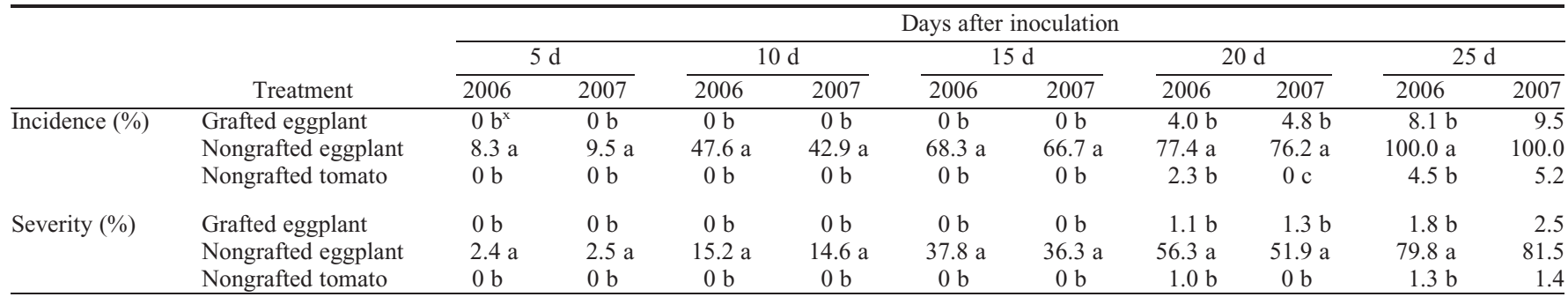

Disease symptoms were classified into five categories based on the proportion of the yellow-bronze-wilted leaves in a plant, i.e., $0=$ no wilted leaves; $1=$ less than $25 \%$ of plant leaves wilted; $2=25 \%$ to $50 \%$ of plant leaves wilted; $3=50 \%$ to $75 \%$ of plant leaves wilted; $4=75 \%$ to $100 \%$ of plant leaves wilted.

${ }^{\mathrm{z}}$ Disease Incidence $=\frac{\text { Number of Infected Plants }}{\text { Total Number of Plants }} \times 100 \%$

${ }^{y}$ Disease Severity Index $=\frac{\left.\sum \text { (Progression } \times \text { Number of Infected Plants }\right)}{\text { Total Number of Plants } \times \text { Highest Progression }} \times 100 \%$

${ }^{x}$ Data in the same column followed by different letters are significantly different at $P \leq 0.05$ for disease incidence and disease severity, respectively.

Table 2. Early yield, total yield, and average fruit weight of grafted eggplant on tomato rootstock and nongrafted eggplant when inoculated with $V$. dahliae during 2006 and 2007 trials.

\begin{tabular}{|c|c|c|c|c|c|c|}
\hline \multirow[b]{2}{*}{ Treatment } & \multicolumn{2}{|c|}{ Early yield (g/plant) } & \multicolumn{2}{|c|}{ Total yield (g/plant) } & \multicolumn{2}{|c|}{ Avg fruit wt (g/fruit) } \\
\hline & 2006 & 2007 & 2006 & 2007 & 2006 & 2007 \\
\hline Grafted eggplant & $710.5 \mathrm{a}^{\mathrm{z}}$ & $905.5 \mathrm{a}$ & $2147.0 \mathrm{a}$ & $2202.0 \mathrm{a}$ & $240.0 \mathrm{a}$ & $290.0 \mathrm{a}$ \\
\hline Nongrafted eggplant & $269.5 \mathrm{~b}$ & $311.5 \mathrm{~b}$ & $678.0 \mathrm{~b}$ & $911.0 \mathrm{~b}$ & $130.0 \mathrm{~b}$ & $190.0 \mathrm{~b}$ \\
\hline
\end{tabular}

${ }^{\mathrm{z}}$ Data in the same column followed by different letters are significantly different at $P \leq 0.05$.

Table 3. Suppressive effect of root exudates from eggplant grafted to tomato rootstock, nongrafted tomato rootstock, and nongrafted eggplant on mycelium growth of $V$. dahliae in vitro.

\begin{tabular}{lcc}
\hline Treatment & $\begin{array}{c}\text { Avg colony } \\
\text { diam }(\mathrm{cm})\end{array}$ & $\begin{array}{c}\text { RI } \\
\text { value }^{z}\end{array}$ \\
\hline Grafted eggplant & $2.85 \mathrm{c}^{\mathrm{y}}$ & $-0.155 \mathrm{a}$ \\
$\begin{array}{l}\text { Nongrafted tomato } \\
\quad \text { rootstock }\end{array}$ & $3.30 \mathrm{~b}$ & $-0.020 \mathrm{~b}$ \\
$\begin{array}{l}\text { Nongrafted eggplant } \\
\text { Distilled water } \\
\quad \text { (control) }\end{array}$ & $3.71 \mathrm{a}$ & $0.090 \mathrm{~d}$ \\
& $3.37 \mathrm{~b}$ & $0.000 \mathrm{c}$ \\
\hline
\end{tabular}

${ }^{\mathrm{z}} \mathrm{RI}$ (allelopathic index) value:

If $\mathrm{T} \geq \mathrm{C}$, then $\mathrm{RI}=1-\mathrm{C} / \mathrm{T} ;$ If $\mathrm{T}<\mathrm{C}$, then $\mathrm{RI}=\mathrm{T} / \mathrm{C}$ -1 . $\mathrm{C}$ is the colony diameter of the control; $\mathrm{T}$ is colony diameter of the treatment; and RI $>0$ indicates stimulation, whereas $\mathrm{RI}<0$ indicates inhibition. The intensity of effect was expressed in RI value.

${ }^{y}$ Data in the same column followed by different letters are significantly different at $P \leq 0.05$.

grafted eggplant were even more evident than those of tomato, whereas the exudates from nongrafted eggplant treatment promoted mycelium growth.

Gas chromatography-mass spectrometry analysis of root exudate extracts. As shown in Table 4, composition of root exudate in grafted eggplant was different from not only the eggplant scion, but also from the tomato rootstock. Ten classes of compounds were detected in the root exudate from grafted eggplant, including hydrocarbon, benzene and benzene derivative, indene, ester, acetone, phenol and alcohol, carbazole, amine, nitrile, and others (4,6,8-trimethyl-azulene and 9-methoxy-fluorene). Interestingly, some of these compounds were not present in root exudates from either the tomato plants or the nongrafted eggplants such as carbazole $(4,5$ dimethyl carbazole, and 2,3,6-trimethyl carbazole), amine (9-ethyl-9H-carbazol-3-amine and 7-methyl-1,8-naphthyridin-2-amine), 4,6, 8-trimethyl-azulene, and 9-methoxy-fluorene. For the grafted eggplant, the relative contents of ester compounds were the highest in the root exudates followed by derivatives of benzene. In contrast, the nongrafted eggplant and tomato treatments showed much higher relative contents of benzene derivatives than that of the ester compounds in the root exudates. Very likely, suppression of mycelium growth by root exudates from grafted eggplants may be attributed to the changes of the root exudate composition as a result of root replacement by grafting.

\section{Discussion}

At present, grafting is considered an effective approach to preventing verticillium wilt and increasing yield in eggplant production (Feng et al., 2000; Song, 2006; Zhou et al., 1997, 2001). Fruit quality of eggplant was not adversely affected by grafting (Wang et al., 2003a; Yang et al., 2005). Assessment of peroxidase isozymes revealed that the changes of isozymogram were more pronounced in rootstocks with higher resistance. In addition, the isozymogram of the roots changed more significantly than that of the above-ground shoot in grafted plants (Zhou et al., 1998). It is now believed that grafting not only modifies the root system directly, but also induces metabolic alterations in scion growth.

It is recognized that allelopathy plays an important role in agriculture and ecological systems. Inhibition of pathogen growth by root exudates has been reported in several studies. On the one hand, root exudates could inhibit the pathogen in rhizosphere directly. On the other hand, root exudates indirectly suppressed the pathogen by attracting antagonistic microbes (Kravchenko et al., 2003; Lugtenberg et al., 1991; Shi, 2004). Root exudates are released by plants to cope with unfavorable soil conditions (Bertin et al., 2003). Allelochemicals exudated from the roots can exhibit either a phytotoxic or stimulatory effect to the releaser, other plant species, and soil microorganisms (Yu, 1999). Phytotoxic compounds such as benzoic acid, ferulic acid, vanillin, and cinnamic acid have been found in root exudates from several vegetable crops, including tomato, cucumber, and eggplant (Kim, 1989; Wang et al., 2006; Yu and Matsai, 1996). Our study of allelochemicals in the root exudates of grafted eggplant indicated that there may be a relationship between the composition of the root exudates and disease response.

In the pathogen challenge study, disease incidence of eggplants inoculated with $V$. dahliae was dramatically decreased through grafting onto tomato. Consistent with previous studies, the results confirmed that the tomato rootstock improved the disease resistance of eggplant to verticillium wilt and resulted in higher yield (Wang et al., 2003a, 2005). The follow-up mycelium growth test further demonstrated the allelopathic suppression of $V$. dahliae by root exudates. The root exudates from grafted eggplant and tomato rootstock plants exhibited significant allelopathic inhibition, whereas the nongrafted eggplants showed promotion of the pathogen compared with control. Zhou et al. (2001) have reported the inhibition of $V$. dahliae by root exudates from both grafted and rootstock plants using wild eggplant rootstock. The inhibitory effects were enhanced with increasing concentration of root extracts. In this study, the tomato rootstock conferred disease resistance to grafted eggplants in the greenhouse pot experiment, whereas surprisingly, the allelopathic suppression to $V$. dahliae by root exudates from grafted eggplant was significantly greater than that of the tomato rootstock. More research is needed to further confirm and understand such findings.

It is speculated that the components of root exudates were altered by grafting to resistant rootstocks. Our previous studies showed that the contents of amino acid, sugar, and phenolic acids in root exudates were changed by grafting with the wild eggplant rootstock. Zhou et al. (2001) reported higher levels of alanine, methionine, isoleucine, and tyrosine in grafted eggplant plants but lower levels of glycine, phenylalanine, and histidine in contrast to nongrafted plants. 
Table 4. Allelochemicals identified by gas chromatography-mass spectrometry and their relative contents in the ether extract of root exudates of grafted eggplant $(\mathrm{E} / \mathrm{T})$, nongrafted eggplant $(\mathrm{E})$, and tomato rootstock $(\mathrm{T})$.

\begin{tabular}{|c|c|c|c|}
\hline \multirow[b]{2}{*}{ Name and class of compound } & \multicolumn{3}{|c|}{ Relative content ${ }^{\mathrm{z}}(\%)$} \\
\hline & $\mathrm{E} / \mathrm{T}$ & $\mathrm{E}$ & $\mathrm{T}$ \\
\hline Hydrocarbon & 6.10 & 1.04 & 3.93 \\
\hline Dodecane & - & - & 0.80 \\
\hline Tricosane & 0.76 & - & 0.31 \\
\hline Octadecane & 0.72 & - & 0.25 \\
\hline Heneicosane & 0.72 & 0.15 & 0.44 \\
\hline Docosane & 0.71 & 0.14 & 0.33 \\
\hline Tetracosane & 0.65 & - & 0.11 \\
\hline Eicosane & 0.63 & - & 0.38 \\
\hline Pentacosane & 0.62 & - & - \\
\hline Nonadecane & 0.47 & - & 0.47 \\
\hline Tridecane & 0.35 & - & - \\
\hline $\begin{array}{l}\text { 1,5,6,7-Tetramethyl-3-phenylbicyclo[3.2.0] } \\
\text { hepta-2,6-diene }\end{array}$ & 0.22 & - & - \\
\hline Tetradecane & 0.15 & 0.58 & 0.62 \\
\hline 1-Octene, 3-(methoxymethoxy)- & - & 0.17 & - \\
\hline Hexacosane & 0.10 & - & - \\
\hline Hexadecane & - & - & 0.09 \\
\hline Heptadecane & - & - & 0.09 \\
\hline Pentadecane & - & - & 0.03 \\
\hline Benzene and benzene derivative & 37.88 & 51.79 & 55.43 \\
\hline (4-Acetylphenyl)phenylmethane & 1.23 & 0.91 & 0.68 \\
\hline Benzene, 1,3-dimethyl-5-(1-methylethyl)- & - & 0.64 & - \\
\hline Benzene, 1-methyl-4-(2-propenyl)- & - & - & 0.43 \\
\hline Benzene, 1,1' -methylenebis[4-methyl- & 0.41 & - & 0.99 \\
\hline Benzene, 1,2,4,5-tetramethyl- & 0.36 & 0.93 & 2.90 \\
\hline Benzene, 1-(1,1-dimethylethyl)-4-ethyl- & 0.33 & - & - \\
\hline Benzene, 1-methyl-4-(1-methylpropyl)- & - & 0.33 & - \\
\hline Benzene, 1-methyl-3-[(4-methylphenyl)methyl]- & 0.27 & - & - \\
\hline Benzene, 1-ethyl-3-(1-methylethyl) & - & 0.25 & 0.19 \\
\hline Benzene, pentamethyl- & 0.22 & 2.50 & 3.84 \\
\hline Benzene, 1,1'-methylenebis[2-methyl- & 0.19 & - & - \\
\hline Benzene, 1,3,5-triethyl- & 0.15 & - & - \\
\hline $\begin{array}{l}\text { Cyclopentanone, 3,3,4-trimethyl-4- } \\
\text { (4-methylphenyl)- }\end{array}$ & 0.08 & - & - \\
\hline Benzene, 1-methyl-2-(2-propenyl)- & 0.05 & - & - \\
\hline Ethylbenzene & - & - & 0.05 \\
\hline Benzene, (1,1-dimethylpropyl)- & 0.04 & - & 0.35 \\
\hline Benzene, 1-methyl-4-(2-propenyl)- & - & - & 0.03 \\
\hline Naphthalene, 2,6-dimethyl- & 6.76 & 6.18 & 4.78 \\
\hline Naphthalene, 2-methyl- & 5.66 & 14.21 & 8.04 \\
\hline Naphthalene, 1,6-dimethyl- & 4.40 & 5.11 & 5.64 \\
\hline Naphthalene, 1-methyl- & 3.84 & 7.50 & 9.98 \\
\hline Naphthalene, 1,4,6-trimethyl- & 2.75 & 2.23 & 0.89 \\
\hline Naphthalene, 1,6,7-trimethyl- & 1.75 & - & 3.24 \\
\hline Naphthalene, 2,3-dimethyl- & 1.52 & - & 0.95 \\
\hline Naphthalene, 1,2-dimethyl- & 1.04 & 1.21 & - \\
\hline Naphthalene & 0.95 & 5.45 & 6.22 \\
\hline Naphthalene, 1,3-dimethyl- & - & 0.84 & - \\
\hline Naphthalene, 1,5-dimethyl- & 0.73 & - & - \\
\hline Naphthalene, 2,3,6-trimethyl- & 0.64 & 0.38 & 0.50 \\
\hline Naphthalene, 1-ethyl- & 0.52 & 0.86 & 0.86 \\
\hline $\begin{array}{l}\text { Naphthalene, 1,2,3,4-tetrahydro-1,6-dimethyl- } \\
\text { 4-(1-methylethyl)-,(1S -cis)- }\end{array}$ & 0.45 & - & - \\
\hline Naphthalene, 1,2,3,4-tetrahydro-5,6-dimethyl- & 0.28 & 0.30 & - \\
\hline Naphthalene, 1,2,3-trimethyl-4-propenyl-, (E)- & 0.10 & - & 1.09 \\
\hline 1,1'-Biphenyl, 4-methyl- & 0.78 & 0.51 & 0.70 \\
\hline 3,3'-Dimethylbiphenyl & 0.43 & - & - \\
\hline 3,5,3',5'-Tetramethylbiphenyl & 0.29 & - & 0.12 \\
\hline 1,1'-Biphenyl, 2-methyl- & 0.26 & - & - \\
\hline 1,1'-Biphenyl, 3,4-diethyl- & 0.24 & - & - \\
\hline $4,4^{\prime}$-Dimethylbiphenyl & 0.21 & - & 0.23 \\
\hline 1,1' -Biphenyl, 3,4' -dimethyl- & 0.19 & - & 0.44 \\
\hline Biphenyl & 0.17 & 0.23 & 0.32 \\
\hline Indene & 0.56 & 1.21 & 0.77 \\
\hline 1H-Indene, 2,3-dihydro-4,7-dimethyl- & 0.51 & 1.21 & 0.69 \\
\hline 1H-Indene, 2,3-dihydro-1,1,3-trimethyl- & 0.05 & - & 0.08 \\
\hline Ester & 53.14 & 39.73 & 23.81 \\
\hline Butanedioic acid, methyl-, bis(1-methylpropyl) ester & 22.19 & 11.52 & 0.93 \\
\hline Hexanedioic acid, bis(2-methylpropyl) ester & 17.70 & 8.21 & 0.68 \\
\hline Butanedioic acid, bis(2-methylpropyl) ester & 6.77 & - & 0.78 \\
\hline Dibutyl phthalate & 5.49 & 2.56 & 2.44 \\
\hline
\end{tabular}

(Continued on next page)
Results from GC-MS analysis revealed 10 chemical classes in the root exudates, many of which are regarded as allelochemicals. Some constituents such as ester, amine, ketone, and cardazole were reported previously as natural botanical products possessing antibacterial properties (Wu et al., 2004). Fatty acid ester was the most abundant component in root exudates released by grafted eggplant and is postulated to be a potential allelochemical and to function at high concentrations (He et al., 2005; Macias, 1995). Recent studies showed that diethyl phthalate could be derived from either bacteria or plants. Keire et al. (2001) reported that Helicobacter pylori secreted diethyl phthalate as a chemotactic factor. Xuan et al. (2006) showed that Rumex japonicus Houtt., a perennial herb widely distributed in the subtropics, produced diethyl phthalate. Diethyl phthalate and derivatives of phthalic acid may be derived from plants. However, the mechanisms for producing such compounds and their explicit biological functions are not well understood and therefore warranted further examination. Meanwhile, the fatty acid esters can be hydrolyzed into acids under certain environmental conditions to impose additional effects on the rhizosphere. Ju et al. (2002) reported that high concentrations of phthalic acid and propanedioic acid could inhibit the growth of Fusarium semitectum, Gliocladium roseum, and Fusarium oxysporum with the most significant effect on $F$. semitectum in particular. Interestingly, phthalic acid and propanedioic acid at low concentrations were found to promote the growth of the pathogens to some extent. It was possible that the soil $\mathrm{pH}$ was decreased as a result of the high concentrations of acids, and the resultant low $\mathrm{pH}$ was unsuitable for pathogen growth. Because fatty acid esters were identified with highest relative content in root exudates from grafted eggplant, more in-depth research is needed to elucidate their role in reducing $V$. dahliae infection.

The composition of root exudates also shed light on the interactions between the eggplant scion and the tomato rootstock. 3Acridinol and alpha-(4-methoxyphenyl)- 2pyridineacetonitrile were detected in both grafted eggplant and tomato rootstock; however, alkalescent compounds such as amine and carbazole were found only in the root exudates of grafted eggplants. It has been suggested that alkalescent substances could inhibit the spore germination and mycelium growth of the pathogen directly (Lugtenberg et al., 1991; Wu et al., 2004). This is the first report of modification of root exudate composition and relative concentration in eggplant grafted onto tomato rootstock.

There is an array of compounds in root exudates with diverse functions. Study of allelochemicals in root exudates presents a novel tool, which may help elucidate disease resistance mechanisms of grafted vegetables. The role of root exudate constituents in selecting disease-resistant rootstocks also needs to be determined. 
Table 4. (Continued) Allelochemicals identified by gas chromatography-mass spectrometry and their relative contents in the ether extract of root exudates of grafted eggplant (E/T), nongrafted eggplant (E), and tomato rootstock (T).

\begin{tabular}{|c|c|c|c|}
\hline \multirow[b]{2}{*}{ Name and class of compound } & \multicolumn{3}{|c|}{ Relative content ${ }^{\mathrm{z}}(\%)$} \\
\hline & $\mathrm{E} / \mathrm{T}$ & $\mathrm{E}$ & $\mathrm{T}$ \\
\hline Butanedioic acid, dibutyl ester & - & 4.95 & - \\
\hline Bis(2-ethylhexyl) phthalate & - & 1.43 & 4.81 \\
\hline $\begin{array}{l}\text { 1,2-Benzenedicarboxylic acid, } \\
\text { bis(2-methylpropyl) ester }\end{array}$ & 0.45 & 11.06 & 13.74 \\
\hline $\begin{array}{l}\text { Dodecanoic acid, 2-(acetyloxy)-1- } \\
\text { [(acetyloxy)methyl]ethyl ester }\end{array}$ & - & - & 0.43 \\
\hline Benzyl Benzoate & 0.26 & - & - \\
\hline $\begin{array}{l}\text { Propanedioic acid, ethyl-, } \\
\text { bis(1-methylpropyl) ester }\end{array}$ & 0.17 & - & - \\
\hline $\begin{array}{l}\text { 2,3-Hexadienoic acid, } \\
\text { 2-methyl-4-phenyl-, methyl ester }\end{array}$ & 0.11 & - & - \\
\hline Aldehyde, acetone & 0.28 & 0.00 & 2.93 \\
\hline 3-Acridinol & 0.28 & - & 0.18 \\
\hline $\begin{array}{l}\text { 3-Buten-1-one, 4-[2,6,6-trimethyl-1 } \\
\text { (or2)-cyclohexen-1-yl]- }\end{array}$ & - & - & 0.12 \\
\hline Acetaldehyde, di-sec-butyl acetal & - & - & 2.63 \\
\hline Phenol, alcohol & 0.03 & 6.90 & 9.93 \\
\hline 4-Butyl-indan-5-ol & 0.03 & - & - \\
\hline Phenol & - & 3.66 & 5.30 \\
\hline Butylated Hydroxytoluene & - & & 0.64 \\
\hline Ethanol, 2-(methylthio)- & - & 3.24 & 3.99 \\
\hline Carbazole & 1.32 & 0.00 & 0.00 \\
\hline Carbazole, 4,5-dimethyl- & 0.76 & - & - \\
\hline Carbazole, 2,3,6-trimethyl- & 0.56 & - & - \\
\hline Amine & 0.44 & 0.00 & 0.00 \\
\hline 9H-Carbazol-3-amine, 9-ethyl- & 0.27 & - & - \\
\hline 1,8-Naphthyridin-2-amine, 7-methyl & 0.17 & - & - \\
\hline Nitrile & 0.12 & 0.00 & 3.20 \\
\hline $\begin{array}{l}\text { 2-Pyridineacetonitrile, .alpha. } \\
\text {-(4-methoxyphenyl)- }\end{array}$ & 0.12 & - & 0.07 \\
\hline Propanenitrile, 3-(methylthio)- & - & - & 3.13 \\
\hline Others & 0.68 & 0.00 & 0.00 \\
\hline Azulene, 4,6,8-trimethyl- & 0.48 & - & - \\
\hline 9-Methoxy-fluorene & 0.20 & - & 一 \\
\hline
\end{tabular}

${ }^{\mathrm{z}}$ The relative content of each component was calculated according to the area normalization method.

\section{Literature Cited}

Alconero, R., W. Robinson, B. Dicklow, and J. Shail. 1988. Verticillium wilt resistance in eggplant, related Solanum species, and interspecific hybrids. HortScience 23:388-390.

Bertin, C., X.H. Yang, and L.A. Weston. 2003. The role of root exudates and allelochemicals in the rhizosphere. Plant Soil 256:67-83.

Bletsos, F.A., C.C. Thanassoulopoulos, and D.G. Roupakias. 1999. Water stress and verticillium severity on eggplant (Solanum melongena L.). J. Phytopathol. 147:243-248.

Bletsos, F.A., C.C. Thanassoulopoulos, and D.G. Roupakias. 2003. Effect of grafting on growth, yield, and verticillium wilt of eggplant. HortScience 38:183-186.

Feng, D.X., B.D. Li, and Y. Wang. 2000. Effects of grafting on the resistance to verticillium wilt and on the biological characteristics of eggplant. China Veg. 4:13-15.

Garber, R.H. 1973. Fungus penetration and development, p. 69-77. Proc. of a work conference in Texas, 30 Aug. to 1 Sept. 1971.

He, H.B., X.X. Chen, R.Y. Lin, W.X. Lin, H.Q. He, X.L. Jia, J. Xiong, L.H. Shen, and Y.Y. Liang. 2005. Chemical components of root exudates from allelopathic rice accession PI312777 seedlings. Chinese J. Appl. Eco. 16:2383-2388.

Ju, H.Y., L.M. Han, S.Q. Wang, and D.L. Cong. 2002. Allelopathic effect of root exudates on pathogenic fungi of root rot in continuous cropping soybean. Chinese J. Appl. Eco. 13:723-727.

Kalloo, D. 1993. Eggplant (Solanum melongena L.), p. 587-604. In: Kalloo, G. and B.O. Bergh (eds.). Genetic improvement of vegetable crops. Pergamon Press, Oxford, UK. cumber (Cucumis sativus) in hydroponic culture. J. Chem. Ecol. 26:1953-1967.

Rice, E.L. 1984. Allelopathy. Ed. II. Academy Press, New York, NY. p. 151-187.

Shi, G.R. 2004. Ecological effects of plant root exudates. Chinese J. Eco. 23:97-101.

Song, M.L. 2006. Effect of grafting cultivation on eggplant resistance to Verticilliun wilt and growth performance. J. Shanxi Agr. Sci. 34:38-39.

Wang, R.H., B.L. Zhou, F.L. Zhang, and Q.F. Zhang. 2005. Allelopathic effects of root extracts on verticillium wilt. Allelo. J. 15:75-84.

Wang, R.H., B.L. Zhou, Q.F. Zhang, and Y.W. Fu. 2003a. Effects of eggplants/tomato grafting on disease resistance and yield. China Veg. 4:10-11.

Wang, R.H., B.L. Zhou, Q.F. Zhang, and Y.W. Fu. 2003b. Physiological characteristics and resistance to Verticillium dahliae in eggplant/ tomato grafted plants. Plant Physio. Commun. 39:330-332.

Wang, R.H., B.L. Zhou, Q.F. Zhang, H. Lian, and Y.W. Fu. 2006. Effects of vanillin and cinnamic acid in root exudates of eggplants on Verticillium dahliae. Acta Ecol. Sin. 26:3152-3155.

Wang, Z.Y., L.H. Gan, H.L. Li, and H.X. Yuan. 2004 Studies on effect of grafting eggplant on different rootstocks on the control of eggplant verticillium wilt. J. Henan Agr. Univ. 38:441-443.

Williamson, G.B. and D. Richardson. 1988. Bioassays for allelopathy: Measuring treatment responses with independent controls. J. Chem. Ecol. 14:181-187.

Wu, C.W., X.F. Du, J.M. Xu, and W.Z. Wang. 2004. Research advances in natural antibacterial constituents from plant origin. Acta Agriculturae Boreali occidentalis Sinica. 13:81-88.

Xuan, T.D., III, M. Chung, T.D. Khanh, and S. Tawata. 2006. Identification of phytotoxic substances from early growth of barnyard grass (Echinochloa crusgalli) root exudates. J. Chem. Ecol. 32:895-906.

Yang, Y., B.L. Zhou, and W. Wang. 2005. Influence of grafting to the content and distribution of nutrient in eggplant fruit. China Veg. 7:10-12.

Yu, J.Q. 1999. Allelopathic suppression of Pseudomonas solanacearum infection of tomato (Solanum lycopersicum) in a tomato-Chinese chive (Allium tuberosum) intercropping system. J. Chem. Ecol. 25:2409-2417.

Yu, J.Q. and Y. Matsai. 1996. Effects of root exudates of cucumber and allelochemicals on the ion uptake by cucumber seeding. J. Chem. Ecol. 22:817-834.

Zhang, S.H., B.L. Zhou, and E.P. Zhang. 2006. Allelopathic effects of Cnidium monnieri and Sophera flavescens on verticillium wilt (Verticillium dahliae) and microbial population in rhizosphere of eggplant. Allelopathy J. 18:153-162.

Zhao, Q.C., N. Zhao, and L. Zhang. 1997. Applied research on increasing resistance to verticillium wilt of eggplant (Verticillium dahliae) by grafting. China Veg. 6:7-9.

Zhou, B.L., G.R. Lin, Y.W. Fu, and Z.Z. Li. 1997. Effect of grafted eggplants on preventing verticillium wilt and increasing production. Liaoning Agr. Sci. 1:53-56.

Zhou, B.L., G.R. Lin, Y.X. Gao, and Y.W. Fu. 1998. The effect of disease resistance with different rootstocks on the peroxidase. Northern Hort. 3:120-121.

Zhou, B.L., H. Jiang, and X. Zhao. 2001. Relation between characteristics of resistance to verticillium wilt of eggplant by graftage and root exudates of eggplant. J. Shenyang Agr. Univ. 32:414-417.

Zhou, B.L. and R.H. Wang. 2002. Progress of graft between different genus of the main vegetable crop. J. Changjiang Veg. Sci. Special:16-17. 